\title{
Optimizing Delivery of HIV Preexposure Prophylaxis for Women in the United States
}

\author{
Erika Aaron, MSN, CRNP, Cori Blum, MD, AAHIVS, Dominika Seidman, MD, MAS, Mary Jo Hoyt, MSN, \\ Joanne Simone, RN, MS, Meg Sullivan, MD, and Dawn K. Smith, MD, MS, MPH ${ }^{6}$
}

\begin{abstract}
Preexposure prophylaxis (PrEP) is a highly effective HIV prevention method; however, it is underutilized among women who are at risk for acquisition of HIV. Women comprise one in five HIV diagnoses in the United States, and significant racial disparities in new HIV diagnoses persist. The rate of new HIV diagnoses among black and African American women in 2015 was 16 times greater than that of white women. These disparities highlight the importance of HIV prevention strategies for women, including the use of PrEP. PrEP is the first highly effective HIV prevention method available to women that is entirely within their control. However, because so few women who may benefit from PrEP are aware of it, few women's healthcare providers offer PrEP to their patients, PrEP has not yet achieved its potential to reduce HIV infections in women. This article describes individual and systemic barriers for women related to the uptake of PrEP services; explains how providers can identify women at risk for HIV; reviews how to provide PrEP to women; and outlines client-centered models for HIV prevention services. Better access to culturally acceptable and affordable medical and social services may offer support to women for consistent and ongoing use of PrEP. This discussion may be used to inform HIV prevention activities for women and guide interventions to decrease racial/ethnic disparities in rates of HIV infection among US women.
\end{abstract}

Keywords: preexposure prophylaxis, HIV risk for women, HIV prevention for women, sexual health

\section{Introduction}

W OMEN COMPRISE ONE IN FIVE HIV diagnoses in the United States, ${ }^{1}$ and significant racial disparities in new HIV diagnoses persist. In 2015, African and Caribbean and African American (black) women accounted for $61 \%$ of the 7,402 estimated HIV diagnoses among women; the rate of new HIV diagnosis among black women was 16 times as high of white women and 5 times as high as Hispanic women. ${ }^{2}$ The proportion of black women with new HIV infections reveals a severe health disparity. Rates of new HIV infection among black women are largely attributed to heterosexual transmission, with $92 \%$ of black women acquiring HIV through sex with a man compared with $68 \%$ for white women. ${ }^{2}$ Geographically, of the 7,402 new infections diagnosed among women in 2015, 4,032 resided in the Southern region of the United States. ${ }^{2}$ An estimated 22\% of transgender women in the United States are living with $\mathrm{HIV},{ }^{3}$ and black transgender women are three times more likely than their white counterparts to have HIV. ${ }^{4}$ These elevated rates suggest that both the stigma of being transgender and structural racism that result in socioeconomic disparities may exacerbate HIV risk. ${ }^{4}$

Preexposure prophylaxis (PrEP) is a highly effective HIV prevention method for men and women; however, it is especially underutilized among women who are at risk for

\footnotetext{
${ }^{1}$ Drexel University College of Medicine, Division of ID/HIV Medicine, Philadelphia, Pennsylvania.

${ }^{2}$ Howard Brown Health Center, Chicago, Illinois.

${ }^{3}$ San Francisco General Hospital, University of California San Francisco, Department of OB/GYN, Reproductive Services, San Francisco, California.

${ }^{4}$ Francois-Xavier Bagnoud Center, School of Nursing, Rutgers, The State University of New Jersey, Newark, New Jersey.

${ }^{5}$ Boston University School of Medicine, Boston, Massachusetts.

${ }^{6}$ Division of HIV/AIDS Prevention, National Center for HIV, Viral Hepatitis, STD, and TB Prevention, Centers for Disease Control and Prevention, Atlanta, Georgia.
}

Disclaimer: The findings and conclusions in this report are those of the authors and do not necessarily represent the official position of the Centers for Disease Control and Prevention.

(C) Erika Aaron, et al., 2018; Published by Mary Ann Liebert, Inc. This Open Access article is distributed under the terms of the Creative Commons Attribution Noncommercial License (http://creativecommons.org/licenses/by-nc/4.0/) which permits any noncommercial use, distribution, and reproduction in any medium, provided the original author(s) and the source are credited. 
HIV. PrEP requires HIV-negative persons to take a daily pill containing two antiretroviral medications. The Food and Drug Administration (FDA) approved a PrEP indication for the fixed dose combination of tenofovir disoproxil fumarate $300 \mathrm{mg}$-emtricitabine $200 \mathrm{mg}$ (TDF-FTC) in $2012^{5}$ and the US Public Health Service released PrEP clinical guidelines in 2014. ${ }^{6}$ As an individual-controlled prevention method, PrEP offers an effective, safe, and private option for women to reduce their risk of HIV acquisition.

In 2015, the US Centers for Disease Control and Prevention (CDC) estimated that 468,000 women in the United States were at significant risk of acquiring $\mathrm{HIV}^{7}$ and may benefit from PrEP. Identification of women who may be exposed to HIV by healthcare systems and individual providers, followed by the provision of PrEP services, is a key public health intervention that has the potential to reduce new HIV infections and reduce the racial and gender disparities in new HIV transmissions. However, data collected from $82 \%$ of US pharmacies between January 1, 2013 and March 31, 2016 demonstrated women accounted for 14\% of PrEP prescriptions, and of these, only $17 \%$ were African American. In addition, one-third of all new PrEP prescriptions were dispensed in the Northeast region, suggesting a need for growth in other regions with high incidence of HIV among women such as southern states. ${ }^{8}$ This article is a review of literature related to PrEP, including individual and systemic barriers for women related to the uptake of PrEP services. We review how providers can assess women's risk for HIV acquisition; describe how to provide PrEP to women; and review a clientcentered approach to HIV prevention care.

\section{Materials and Methods}

We reviewed a previously completed systematic collection of PrEP literature published from January 2010 through June 2017 to identify those publications related to women. Searches were conducted of MEDLINE, Embase, CINAHL, and Cochrane Library databases. The search strategy used the following criteria in the title, abstract, keyword heading word, subject heading fields: Pre-Exposure Prophylaxis/OR Chemoprevention/OR PrEP OR [topical adjacent to (prevention OR prophylaxis OR microbicide* OR gel OR pericoital OR precoital OR vaginal OR rectal OR anal)] OR chemoprophylaxis AND (exploded terms) Anti-HIV Agents/ OR Anti-Retroviral Agents/OR HIV Infections/pc OR \{[HIV OR human immunodeficiency virus] AND [antiretroviral* OR anti-retroviral* OR antiretrovirus* OR antiretrovirus* OR Truvada OR tenofovir OR emtricitabine OR (TDF ADJ5 FTC)]\} AND NOT animals.

Two scientists at the CDC independently reviewed the citations and removed those that were not published in English, did not contain data (e.g., editorials, reviews, news reports), or did not contain data about oral TDF/FTC for PrEP. The next step was to screen citations to remove those that did not contain new data about oral PrEP (data/analyses not previously published). Abstracts or full articles were then read, and publications were categorized into the groups listed above. The coding by the two reviewers was then compared and discrepancies were reconciled. Citations with no new data about daily oral PrEP with TDF/FTC were deleted from the updated reference file. The authors of this article received a copy of the reference file and then reviewed the citations for those addressing risk of HIV and sexually transmitted infections (STIs) specifically for women.

\section{Results}

Individual and systemic barriers for the uptake of PrEP services for women

US women have limited knowledge of PrEP, creating a major barrier for self-referral to PrEP services. However, once informed, women express a willingness to use PrEP, and African American are women more likely than white women to consider its use. ${ }^{9}$ Factors that have been shown to influence women's decision-making about the use of PrEP are the following: cost, peer perspectives, having a woman-controlled prevention strategy, physician input, and ease of accessing services and medication near to their homes. ${ }^{10-13}$ Women express concern that medical providers who are unaware of the guidelines for PrEP use in women will be less willing to offer and prescribe PrEP. ${ }^{13}$

A major barrier to PrEP uptake by women is the lack of perception of risk for HIV acquisition. ${ }^{14}$ Black women, for example, who may not perceive themselves at risk for HIV have a higher probability of exposure to HIV, despite practicing the same sexual behavior (condom use, number of partners) as other women. ${ }^{15}$ Being in a sexual network with higher rates of HIV and STIs coupled with low awareness of partners' status or risk factors, increase the risk of HIV acquisition even with protective sexual behavior. ${ }^{16}$ Aholou et al. found that black women were more likely to have partners who they perceived to be nonmonogamous and were more likely than women of other racial groups to report protective behaviors such as condom use at last vaginal or anal sex. ${ }^{15}$ This is consistent with other studies that have described higher rates of condom use among black women, ${ }^{17,18}$ suggesting that other social and structural factors contribute to HIV acquisition risk for these women. ${ }^{16}$

Specifically, sexual networks, partner selection practices, ${ }^{19}$ incarceration, ${ }^{20,21}$ low awareness of HIV status or partner's status, ${ }^{22}$ low male-to-female sex ratios, ${ }^{16}$ poverty, ${ }^{16,23}$ low educational attainment, ${ }^{16,23}$ and lack of access to healthcare ${ }^{24}$ may contribute to increased risk of HIV acquisition among black women. Racial segregation along with mass incarceration of black men may limit the number of available partners to black women and thus may contribute to the formation of insular sexual networks with overlapping concurrent partners. As a result, many black women in these communities face greater exposure to HIV acquisition with each sexual encounter, and may underestimate this consequence. ${ }^{16}$

Knowledge of a partner's HIV status can lead to reductions in risky sexual behaviors. ${ }^{25,26}$ However, women are significantly less likely than men to know their partners' HIV status. ${ }^{27}$ In addition, men living with HIV who have sex with both men and women less often notify female sex partners of their seropositivity. ${ }^{28}$ The Women's HIV SeroIncidence Study (HPTN 064) examined the prevalence and characteristics associated with knowledge of partner's serostatus among a cohort of African American women in the United States. ${ }^{29}$ The study found that $43 \%$ of the African American women living in high poverty and high HIV prevalence areas were unaware of their most recent male partner's HIV status. The women with lower knowledge of partner serostatus was associated with having 
Table 1. Assessment to Identify Women Who May Benefit from Daily

Oral Antiretroviral Preexposure Prophylaxis

Ask

- Has she ever had an HIV test? If yes, does she know the result? If never tested, or doesn't know the result, or hasn't been tested in $>1$ year, offer and provide HIV test.

- Has she been sexually active in the past 6 months? If sexually active, ask:

$\circ$ About gender of partner(s)

$\circ$ About what body parts she uses for sex (will help guide education re: protective levels and also which body parts to screen for gonorrhea and chlamydia trachomatis)

$\circ$ If she knows the HIV status of her partner(s);

- if partner is positive, whether she knows their HIV treatment and viral load status

- if they are aware of partner's concurrency, partner drug use, partner recent incarceration history, and if significantly older age.

$\circ$ About methods she currently uses/prefers for HIV and STD prevention

$\circ$ If diagnosed with a bacterial STD in the last 6 months

- Is she interested in/intending to become pregnant?

- If interested in pregnancy, discuss safe conception methods

- If not interested in pregnancy, ask about contraceptive methods she is using; if none, discuss contraceptive options

- Has she ever injected drugs that were not prescribed for her?

$\circ$ If yes, when did she last inject? What drug(s)? Is she using clean injection equipment? Is she sharing injection equipment?

two or more sex partners, suggesting that women most at risk for HIV are least likely to know of their infection risk. Other factors identified were food insecurity, partner age $>35$, intimate partner violence (IPV), partner's sexual concurrency with multiple women, prevalence of substance abuse, and sex exchange for financial and in-kind resources in their communities. ${ }^{30}$

Transgender women, women who inject drugs, and women who exchange sex for money or commodities juggle a multitude of priorities in the face of formidable barriers to care. Although HIV incidence is high among these communities, prevention efforts specifically for these populations have been minimal. Such interventions would require attention to the structural, social, and individual factors influencing HIV risk in these groups, including unemployment, stigma, discrimination, criminalization, homelessness, sexual assault, physical abuse, and lack of familial support. ${ }^{31}$

An estimated $18 \%(115,000)$ of persons in the United States who inject drugs have indications for PrEP use. ${ }^{7}$ Women who inject drugs are more likely to engage in sex with partners who inject drugs. ${ }^{32}$ In addition, women who share needles are most likely to do so with their sexual partners, and women are frequently injected by their sexual partners. ${ }^{33}$ PrEP offers a unique prevention tool for this population as it protects against HIV transmitted through both sexual contact and injection drug use. ${ }^{34}$ Other risk reduction methods include the following: destigmatizing injection drug use, ensuring women's access to syringe programs, opioid substitution therapy, and supervised injection facilities. Women who exchange sex for money or commodities face barriers to care, which include facing stigmatization at medical care facilities.

\section{Identifying women who may benefit from PrEP}

Factors associated with vulnerability to HIV include a history of inconsistent or no condom use; recent diagnosis of an STI; exchange of sex for commodities (such as money, shelter, food, or drugs); use of intravenous drugs and/or alcohol dependence; having a partner(s) with HIV; having had a partner(s) of unknown HIV status with any of the factors previously listed; women living in communities with high
HIV prevalence; and being in a high-risk sexual network with low awareness of partners' status or risk factors. Partner characteristics such as prior incarceration, injection drug use, concurrent partnerships with women and/or men, and those partners who are unaware of their HIV infection represent a substantial risk factor to women. Women who have condomless sex with a partner living with HIV and whose viral load is not suppressed are at significant risk of HIV acquisition. Longitudinal studies among women have shown that a diagnosis of gonorrhea or syphilis is highly associated with the risk of HIV acquisition in a mean subsequent time of 3.6 years. ${ }^{35}$ However, while population-based risk factors would make screening women for PrEP eligibility easier, the nuances of a woman's vulnerability to HIV likely go beyond scripted screening questions. Careful history taking around sexual health and trauma experiences, informed by a keen understanding of social determinants of health, may provide the opportunity to discuss expanded HIV prevention options with women who are at risk for HIV exposure. ${ }^{36}$ Table 1 is an example of an assessment to identify potential candidates for PrEP.

A history of trauma has been identified as a significant risk factor for HIV acquisition. ${ }^{37}$ Women living with HIV have disproportionate rates of exposure to trauma, defined as experiencing or witnessing sexual or physical violence resulting in an intense emotional response, compared to those without HIV. ${ }^{38}$ Women in violent relationships have few feasible HIV risk reduction options since traditional prevention methods, male and female condoms, are dependent on a partner's cooperation. PrEP has critical advantages for women in violent relationships, including potential use without their partners' active involvement, knowledge, or consent, coital independence, dual protection against sexual and injection HIV risk, and an opportunity for connection to primary care and social services. ${ }^{34}$ Caring for and counseling women affected by trauma require specific approaches that foster a therapeutic clinical environment, routine screening for trauma, and a comprehensive response program that promotes safety and healing. ${ }^{39}$ However, some women may not disclose experiences of violence, ${ }^{40}$ just as some women may choose not to disclose vulnerabilities to HIV. Thus, it is 
Table 2. Identifying Gender and Sexual Orientation

\begin{tabular}{ll}
\hline What sex were you assigned at birth? & $\square$ Male \\
& $\square$ Female \\
& $\square$ Decline to State \\
What is your sex or current gender? & $\square$ Male \\
& $\square$ Female \\
& $\square$ Transmale/Transman \\
& $\square$ Tansfemale/Transwoman \\
& $\square$ Prefer to self-describe \\
& $\square$ Prefer not to say \\
& $\bullet$ Are you sexually active? \\
& $\bullet$ When was the last time you had sex? \\
Questions about your sexual health and sexuality & $\bullet$ When you have sex, do you do so with men, women, or both? \\
& $\bullet$ How many sexual partners have you had during the last year? \\
& $\bullet$ Do you have any desires regarding sexual intimacy that you \\
& would like to discuss?
\end{tabular}

critical to provide education and information about PrEP to all women as part of comprehensive HIV preventive care so as not to miss women who do not disclose specific vulnerabilities to HIV.

\section{Adherence}

The efficacy of PrEP is dependent on adherence for effective drug concentration to reach vaginal, cervical, and anal tissues. Maximum intracellular concentration of tenofovir varies with specific tissues: cervicovaginal tissue penetration takes up to 20 days, rectal tissue takes up to 7 days, and serum penetration takes up to 20 days to reach maximum intracellular concentration. ${ }^{6}$ To assure effective protection, it is important to emphasize the use of additional HIV prevention strategies (e.g., condoms) during the time frame when drug concentration may not yet achieve protective concentration (20 days for vaginal exposure and 7 days for rectal exposure). Pharmacokinetic studies suggest that PrEP requires a minimum adherence of 6 of 7 doses/week ( $85 \%$ adherence) to protect cervicovaginal tissue from HIV, and adherence of 2 of 7 doses/week (28\% adherence) to protect colorectal tissue. ${ }^{39}$ The efficacy of PrEP in women varied widely across clinical trials from $26 \%$ to $81 \%$ and corresponded with adherence. ${ }^{41}$ PrEP was nonefficacious when adherence was low ${ }^{42}$ and was most efficacious when adherence was high. ${ }^{43,44}$

PrEP may not be suitable for all persons at risk of HIV for reasons such as inability to adhere to a daily pill regimen and fear of partner violence. However, PrEP may be desirable for persons during "seasons of high risk," that is period of times when a person is more vulnerable to HIV. Perception of risk has demonstrated an important facilitator of adherence. ${ }^{45}$ This was demonstrated in the FEM-PrEP study done in Kenya, South Africa, and Tanzania, where $70 \%$ of women perceived little risk for acquiring HIV; thus, adherence and efficacy were low. ${ }^{45}$ Strategies that providers can use to promote adherence include facilitating accurate knowledge and understanding of medication benefits and requirements, reminder calls or text messages, promoting self-efficacy for adherence, providing a formal support program that includes peer support, and providing resources to address mental health, substance use problems, economic and housing constraints. ${ }^{46}$ Trust and the support of a partner have been shown to reinforce adherence with participants in the African Partners PrEP trial reporting that partners living with HIV often reminded, supported, and reinforced medication adherence. ${ }^{47}$ Providers can encourage partner support if the woman has disclosed her interest in PrEP to her partner, to help achieve adherence. However, if partner trust and support are not possible, providers can reinforce that PrEP provides a method of HIV prevention that does not require partner knowledge.

For young women who have limited experience with healthcare utilization and lack of experience with long-term medications adherence, daily PrEP presents additional challenges. This has been demonstrated by low adherence rates to oral contraception, resulting in high rates of unintended pregnancy. PrEP adherence support can focus on practical issues: medication storage, reminders for carrying doses when away from home, pill taking behaviors based on daily routines, and partner/family/peer support.

\section{Discussion}

PrEP is the first highly effective HIV prevention method available to US women that is entirely within their control. However, due to lack of awareness of PrEP by women who would benefit from its use, and insufficient knowledge of PrEP by women's healthcare providers, PrEP is not yet achieving its potential to reduce the number of new diagnoses occurring among women. With strong evidence for the effectiveness and safety of PrEP, it becomes essential to deliver PrEP services to women in ways that meet their needs.

PrEP is now a standard prevention option and should not be presented hesitantly. Providers briefly describe to the patient how it works, its effectiveness and safety, what ongoing care is required, resources available to cover the cost, answer any questions, and, if she is interested, initiate PrEP care. ${ }^{36}$ See Fig. 1 which describes how to prescribe PrEP.

\section{Facilitators for provision of PrEP for women}

Black women, who comprise $62 \%$ of new HIV diagnoses among all women, are more likely than white women to have concurrent sex partners and partners who they perceived to be nonmonogamous, yet, use protective behaviors more frequently, such as condom use at last vaginal or anal sex. This suggests that other social and structural factors (e.g., higher community baseline HIV and STD prevalence, inequality of health resources due to poverty, racism, gender power imbalance, and incarceration) likely contribute to HIV acquisition 


Laboratory
Tests

\begin{tabular}{l}
$\begin{array}{l}\text { Complete } \\
\text { insurance and/or } \\
\text { medication } \\
\text { assistance } \\
\text { paperwork }\end{array}$ \\
$\begin{array}{l}\text { Uninsured patients } \\
\text { If the patient has no insurance, patient can be referred to an insurance counselor if available and apply for } \\
\text { public health PrEP access programs or free drug through GileadAdvancingAccess.com }\end{array}$ \\
$\begin{array}{l}\text { Uninsured patients } \\
\text { If insured, patient can apply for copay assistance (http://www.silead.com/responsibility/us-patient- } \\
\text { access/truvada\%20for\%20prep\%20medication\%20assistance\%20program) } \\
\text { Counsel patient to call clinic if insurance denied so that appeal can be submitted promptly }\end{array}$ \\
\hline
\end{tabular}

B

\begin{tabular}{|l|}
\hline Initiation of PrEP \\
\hline
\end{tabular}

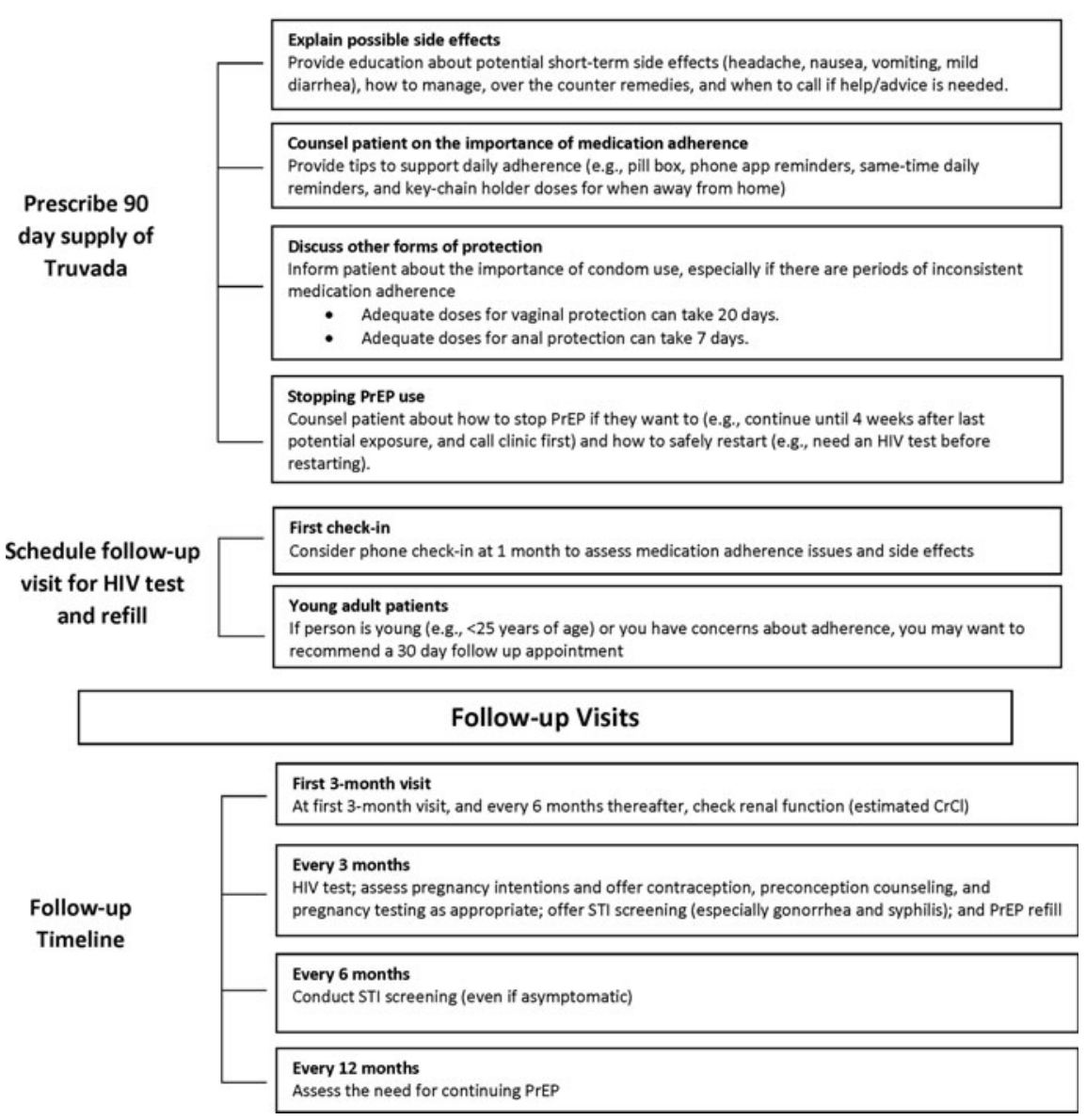

FIG. 1. A and B: Prescribing PrEP for women. PrEP, preexposure prophylaxis. 
risk for black women. ${ }^{16}$ Awareness of factors impacting women's HIV acquisition risk allows clinicians to tailor their history taking and shared decision-making practices to increase women's access to PrEP. Medical providers can help raise awareness of PrEP among potential users through clear positive messaging that are culturally sensitive, engaging partners when appropriate, integrating HIV prevention services with the delivery of other services that meet women's needs such as family planning, pregnancy care, emergency contraception, postexposure prophylaxis, and IPV counseling.

A perceived barrier to PrEP use is that medication cost is formidable. This has fortunately been addressed through coverage by most public and private insurers and several state health departments offer PrEP-assistance programs to support access for uninsured people (CA, IL, MA, NY, WA). In addition, the PrEP medication assistance plan through Gilead Sciences provides free medication to those who are uninsured and low income $(<500 \%$ of federal poverty level); for those who are insured, this plan offers coverage of insurance copays up to $\$ 4800$ per year (GileadAdvancingAccess.com).

Addressing patients' sexual health is integral to assuring successful implementation of PrEP services for lesbian, gay, bisexual, and transgender (LGBT) persons. Medical providers can facilitate open conversations about their patient's sexual orientation and gender identity and ensure that there are messages that LGBT people are welcome in their medical offices. When patients feel that they are respected, they are likely to respond accurately and honestly to sensitive questions, which may facilitate discussions of risk reduction interventions. Intake forms and provider-initiated medical history questions should include how patients self-identify their sexual orientation and gender identity. Patient histories should address sexual behavior, sexual health, sexual orientation (including identity, behavior, and attraction), and gender identity. ${ }^{48}$ Clinical prevention interventions for transgender persons include routine screening for STIs and HIV, cultural competency training directed at provider attitudes and behavior toward transgender patients, mutual patient-provider trust, and the bundling of comprehensive HIV prevention services with medical and psychosocial services. ${ }^{49}$ See Table 2 to help identify gender and sexual orientation.

Understanding unique motivations and barriers to care of sex workers, including stigmatization at medical care facilities, can contribute to successful uptake of PrEP for women who exchange sex for money or commodities. This can be facilitated by cultural competency training for healthcare providers, colocation and integration of services such as STI, reproductive health, family planning, HIV and prevention care, gender affirming care, coupled with peer training to provide outreach, one on one counseling, and group discussions.

\section{A client centered approach}

The goal of PrEP implementation is to ensure that clients are well informed about PrEP, and are empowered to access and utilize it if they choose to use this method of HIV prevention. A way for providers to achieve this goal is by using a client-centered approach that considers women's preferences, needs, and values. Shared decision-making provides one such approach, which can be appropriately applied to clinical scenarios, in which there are multiple options. In the realm of HIV prevention, options include condoms, postexposure prophylaxis, regular partner testing, treatment as prevention of a partner living with HIV, and STI testing and treatment. The clinician shares evidence-based information, while the client offers her preferences and values; together, they arrive at a patient-centered choice. ${ }^{36,50}$ This process cannot be a onetime endeavor. Rather, early PrEP studies indicate the importance of assessing and reassessing vulnerabilities to HIV exposure and interest in and/or satisfaction with PrEP, as clients' life situations, values, and preferences regarding HIV prevention change over time. ${ }^{51}$ Building trust has been identified as an evidence-based best practice in family planning counseling, to both acknowledge a history of mistreatment and distrust, and to promote effective shared decision-making and client-centered care. ${ }^{52}$

Altering the risk perception, historical, social, environmental, and structural determinants of health and healthcare access for women at substantial risk for HIV and subsequent infection are daunting but necessary long-term tasks. Raising awareness of PrEP among potential users, using messages that are culturally sensitive, and training healthcare providers to deliver PrEP effectively are achievable in the near term if we focus our efforts appropriately. If we successfully link the clinical delivery of PrEP with wrap-around services to support medication adherence by helping women juggle competing life issues, such as access to insurance, substance abuse treatment, mental health services, and social service support, PrEP will contribute to the goal of making new HIV infections rare in women.

\section{Author Disclosure Statement}

No competing financial interests exist.

\section{References}

1. Centers for Disease Control and Prevention. HIV Surveillance Report, 2015; vol. 27. 2016. Available at: www.cdc. gov/hiv/library/reports/hiv-surveillance.html (Last accessed January 31,2017$)$.

2. Centers for Disease Control and Prevention. HIV Surveillance in Women, 2015. Available at: www.cdc.gov/hiv/library/slide Sets/index.html (Last accessed January 31, 2017).

3. Baral SD, Poteat T, Strömdahl S, et al. Worldwide burden of HIV in transgender women: A systematic review and meta-analysis. Lancet Infect Dis 2013;13:214-222.

4. Herbst JH, Jacobs ED, Finlayson TJ, et al. Estimating HIV prevalence and risk behaviors of transgender persons in the United States: A systematic review. AIDS Behav 2008;12: $1-17$.

5. Grady D. FDA advisory panel backs preventive use of HIV drug. New York Times 2012:D5.

6. US Public Health Service. Preexposure prophylaxis for the prevention of HIV infection in the United States-2014: A clinical practice guideline. 2014. Available at: www.cdc .gov/hiv/pdf/prepguidelines2014.pdf (Last accessed November 21, 2017).

7. Smith DK, Van Handel M, Wolitski RJ, et al. Vital signs: Estimated percentages and numbers of adults with indications for preexposure prophylaxis to prevent HIV acquisition-United States, 2015. J Miss State Med Assoc 2015; 56:364-371.

8. Bush S, Rawlings $\mathrm{K}$, Magnuson $\mathrm{D}$, et al. Utilization of emtricitabine/tenofovir (FTC/TDF) for HIV pre-exposure prophylaxis in the United States by gender (2013-1Q2016). 
Abstracts of the HIV Glasgow supplement. J Int AIDS Society 2016;19 (Suppl 7):Abstract O314.

9. Wingood GM, Dunkle K, Camp C, et al. Racial differences and correlates of potential adoption of preexposure prophylaxis: Results of a national survey. J Acquir Immune Defic Syndr 2013;63 Suppl 1:S95-S101.

10. Auerbach JD, Banyan A, Riordan M. Will and should women in the U.S. use PrEP? Findings from a focus group study of at-risk HIV-negative women in Oakland, Memphis, San Diego, and Washington, DC. XIX International AIDS Conference (July 27, 2012). Washington, DC. Abstract FRLBD04.

11. Goparaju L, Experton LS, Praschan NC, et al. Women want pre-exposure prophylaxis but are advised against it by their HIV-positive counterparts. J AIDS Clin Res 2015; $6: 1-10$.

12. Auerbach JD, Kinsky S, Brown G, et al. Knowledge, attitudes, and likelihood of pre-exposure prophylaxis (PrEP) use among US women at risk of acquiring HIV. AIDS Patient Care STDS 2015;29:102-110.

13. Smith DK, Toledo L, Smith DJ, et al. Attitudes and program preferences of African-American urban young adults about pre-exposure prophylaxis (PrEP). AIDS Educ Prev 2012;24:408-421.

14. Hodder SL, Justman J, Haley DF, et al.; HIV Prevention Trials Network Domestic Prevention in Women Working Group. Challenges of a hidden epidemic: HIV prevention among women in the United States. J Acquir Immune Defic Syndr 2010;55 Suppl 2:S69-S73.

15. Aholou T, Hubbard McCree D, Oraka E, et al. Sexual risk and protective behaviors among reproductive-aged women in the United States. J Womens Health 2017;00:1-11.

16. Adimora AA, Schoenbach VJ, Bonas DM, Martinson FA, Donaldson KH, Stancil TR. Concurrent sexual partnerships among women in the United States. Epidemiology 2002;13: 320-327.

17. Reece M, Herbenick D, Schick V, Sanders SA, Dodge B, Fortenberry JD. Condom use rates in a national probability sample of males and females ages 14 to 94 in the United States. J Sex Med 2010;(5 Suppl):266-276.

18. Soler H, Quadagno D, Sly DF, Riehman KS, Eberstein IW, Harrison DF. Relationship dynamics, ethnicity and condom use among low-income women. Fam Plann Perspect 2000; $1: 82-101$.

19. Doherty IA, Schoenback JV, Adimora AA. Sexual mixing patterns and heterosexual HIV transmission among African Americas in the southeastern United States. J Acquir Immune Defic Syndr 2009;52:114.

20. Pouget ER, Kershaw TS, Miccolai LM, Ickovics JR, Blankenship KM. Associations of sex ratios and male incarceration rates with multiple opposite-sex partners; potential social determinants of HIV/STI transmission. Public Health Rep 2010;125(Suppl 4):70-80.

21. Brewer RA, Magnus M, Kuo I, Wang L, Liu TY, Mayer $\mathrm{KH}$. The high prevalence of incarceration history among black men who have sex with men in the United States; associations and implications. Am J Public Health Res 2014;104:448-454.

22. Seth P, Walker T, Hollis N, Figueroa A, Belcher L. HIV Testing and service delivery among Blacks or African Americans-61 Health Department Jurisdictions, United States, 2013. MMWR Morb Motral Wkly Rep 2015;64:87-90.

23. Aral SO, Adimora AA, Fenton KA. Understanding and responding to disparities in HIV and other sexually trans- mitted infections in African Americans. Lancet 2008;372: 337-340.

24. Blackstock OJ, Frew P, Bota D, et al. Perceptions of community HIV/STI risk among US women living in areas with high poverty and HIV prevalence rates. J Health Care Poor Underserved 2015;26:811-823.

25. Benki-Nugent S, Chung MH, Ackers M, et al. Knowing a sexual partner is HIV-1-uninfected is associated with higher condom use among HIV-1-infected adults in Kenya. Sex Transm Dis 2011;38:808-810.

26. Marks G, Crepaz N, Senterfitt JW, Janssen RS. Metaanalysis of high-risk sexual behavior in persons aware and unaware they are infected with HIV in the United States: Implications for HIV prevention programs. J Acquir Immune Defic Syndr 2005;39:446-453.

27. Bachanas P, Medley A, Pals S, et al. Disclosure, knowledge of partner status, and condom use among HIV-positive patients attending clinical care in Tanzania, Kenya, and Namibia. AIDS Patient Care STDs 2013;27:425-435.

28. McKay T, Mutchler M. The effect of partner sex: Nondisclosure of HIV status to male and female partners among men who have sex with men and women (MSMW). AIDS Behav 2011;15:1140-1152.

29. Jennings L, Rompalo A, Wang J, et al. Prevalence and correlates of knowledge of male partner HIV testing and serostatus among African-American women living in high poverty, high HIV prevalence communities (HPTN 064). AIDS Behav 2015;19:291-301.

30. Frew P, Parker K, Vo L, et al. Socioecological factors influencing women's HIV risk in the US: Qualitative findings from the women's HIV SeroIncidence study (HPTN 064). BMC Public Health 2016;16:803.

31. Grant JM, Mottet LA, Tanis J, et al. Injustice at Every Turn: A Report of the National Transgender Discrimination Survey. Washington, DC: Nation Center for Transgender Equality and National Gay and Lesbian Task Force; 2011. Available at: www.thetaskforce.org/static_html/downloads/ reports/reports/ntds_full.pdf (Last accessed July 10, 2017).

32. Decker MR, Miller E, McCauley HL, et al. Recent partner violence and sexual and drug-related STI/HIV risk among adolescent and young adult women attending family planning clinics. Sex Transm Infect 2014;90:145-149.

33. MacRae R, Aalto E. Gendered power dynamics and HIV risk in drug-using sexual relationships. AIDS Care 2000;12:505-516.

34. Braksmajer A, Senn TE, McMahon J. The potential of preexposure prophylaxis for women in violent relationships. AIDS Patient Care STDs 2016;30:274-281.

35. Peterman TA, Newman DR, Maddox L, et al. Risk for HIV following a diagnosis of syphilis, gonorrhea or chlamydia: 328,456 women in Florida, 2000-2011. Int J STD AIDS 2015;26:113-119.

36. Seidman D, Weber S. Integrating preexposure prophylaxis for human immunodeficiency virus prevention into women's health care in the United States. Obstet Gynecol 2016; 128:37-43.

37. Machtinger EL, Cuca YP, Khanna N, et al. From treatment to healing: The promise of trauma-informed primary care. Women's Health Issues 2015;25:193-197.

38. Machtinger EL, Wilson TC, Haberer JE, et al. Psychological trauma and PTSD in HIV-positive women: A metaanalysis. AIDS Behav 2012;16:2091-2100.

39. Cottrell ML, Yang KH, Prince HM, et al. A translational pharmacology approach to predicting outcomes of preexposure prophylaxis against HIV in men and women using 
tenofovir disoproxil fumarate with or without emtricitabine. J Infect Dis 2016;21455-64.

40. O’Doherty LJ, Taft A, Hegarty K, et al. Screening women for intimate partner violence in healthcare settings: Abridged Cochrane systematic review and meta-analysis. BMJ 2014;348:g2913.

41. Campbell JD, Herbst JH, Koppenhaver RT, et al. Antiretroviral prophylaxis for sexual and injection drug use acquisition of HIV. Am J Prev Med 2013;44(1S2):S63-S69.

42. Van Damme L, Corneli A, Ahmed K, et al. Preexposure prophylaxis for HIV infection among African women. $\mathrm{N}$ Engl J Med 2012;367:411-422.

43. Baeten J, Donnell D, Ndase P, et al. Antiretroviral prophylaxis for HIV prevention in heterosexual men and women. N Engl J Med 2012;367:399-410.

44. Thigpen MC, Kebaabetswe PM, Paxton LA, et al. Antiretroviral preexposure prophylaxis for heterosexual HIV transmission in Botswana. N Engl J Med 2012;367:423-434.

45. Haberer J, Baeten J, Celum C, et al. High adherence among HIV-1 serodiscordant couples in the partners PrEP Ancillary Adherence Study. In Proceedings of the 7th International Conference on HIV Treatment and Prevention Adherence, Miami, FL. Abstract 80026. 2012

46. Koenig L, Lyles C, Smith D. Adherence to antiretroviral medications for HIV pre-exposure prophylaxis: Lessons learned from trials and treatment studies. Am J Prev Med 2013;44(1S2):S91-S98.

47. Ware NC, Wyatt MA, Haberer JE, et al. What's love got to do with it? Explaining adherence to oral antiretroviral pre- exposure prophylaxis for HIV-serodiscordant couples. J Acquir Immune Defic Syndr 2012;59:463-468.

48. Bradford JB, Cahill S, Grasso C, et al. Policy Focus: How to gather data on sexual orientation and gender identity in clinical settings. Fenway Health. Available at: http://thefenwayinstitute .org/documents/Policy_Brief_HowtoGather..._v3_01.09.12 .pdf (Last accessed July 10, 2017).

49. Neumann MS, Finlayson TJ, Pitts NL, et al. Comprehensive HIV prevention for transgender persons. Am J Public Health 2017;107:207-212.

50. Makoul G, Clayman ML. An integrative model of shared decision making in medical encounters. Patient Educ Couns 2006;60:301-312.

51. Grant RM, Glidden DV. HIV moments and pre-exposure prophylaxis. Lancet 2016;387:1507-1508.

52. Dehlendorf C, Krajewski C, Borrero S. Contraceptive counseling: Best practices to ensure quality communication and enable effective contraceptive use. Clin Obstet Gynecol 2014;57:659-673.

Address correspondence to: Erika Aaron, MSN, CRNP Drexel University College of Medicine 1427 Vine Street, 5th floor Philadelphia, PA 19102

E-mail: eaaron@drexelmed.edu 